that time until the time of writing'(Sept. 2nd) there has been steady improvement in every way. The fits have never returned nor has there been any spasm of the arm or the leg. Her mental condition has so improved that she can be trusted to go shopping for trifles for her mother. She has been left in the house for hours at a time with only her younger brother-which, in my opinion, is a risky proceeding - and has been "as good as gold." She calls me "the doctor" and addresses other people by their right names. Her gait is no longer shambling. She amuses herself for a long time together by looking at pictures and she is learning the names of animals, \&c., with the facility of an average child of four or five years of age.

Bitterne, Hants.

\section{NATURE'S ALKALINE TREATMENT OF GOUT AND RHEUMATISM BY THE USE OF NATURAL ALKALINE THERMAL WATERS. ${ }^{1}$}

BY CARL N. BRANDT, M.D., RESIDENT PHYSICIAN, HOT SPRINGS, VIRGINIA, U.S.A.

MY only excuse for attempting any addition to the already overdone subject of rheumatism and gout is that in an experience of a number of years in the treatment of these conditions solely certain clinical facts have been impressed upon me to so great an extent that I feel that the lessons learned by clinical work may be of some value to those of the profession who are called upon to deal with the subacute and chronic forms of so-called gout and rheumatism. To go into the theories that have been advanced in the past is not my purpose, but merely to try to show why and how results are obtained by the use of natural alkaline thermal waters, internally and externally, in a large number of cases where all other means had failed. That such is the case can, I am sure, be testified to by almost all the leading medical men of the day, and $m y$ only surprise is that they fail to understand how such results are obtained. No treatment gives rise to so much disbelief as the use of water as a therapeutic agent, and the idea that after the use of all the drugs, the so-called specifics, the alkalies, and the salines, relief should be given by the use of water is by many considered absurd, and the man who advocates such treatment is dubbed a fanatic. The profession, as a rule, may be said to be satisfied that the most approved treatment for these conditions is the so-called alkali treatment, and yet they express surprise that good results should be obtained by the use of alkaline waters. Have they ever stopped to consider that, after all, the so-called water cures or treatment for gout or rheumatism are nothing more or less than the alkaline treatment, differing only in the fact that the alkali is, on the one hand, supplied by the druggist, and on the other by nature? Such is the case. All the water cures for these conditions consist in the use of alkaline waters, not only internally, but also in the form of baths. The use of the alkaline waters is but one factor in the proposition. Another is that when properly used we have the application of the alkaline treatment under the best circumstances and with the best possible surroundings. Quite possibly the patient's physician at home will have laid the fullest stress upon the proper diet, exercise, mental rest, \&c., that the patient is to have, in addition to the medication advised, but (and herein lies the kernel of the nut) the patient does not follow these instructions. He will take his pill or teaspoonful of medicine with absolute precision and regularity, but he has no time for exercise and dieting. After finishing his business and following his pleasure he may give these a half-hearted attention for a day or two, but there it, as a rule, ends. These are not conditions to be helped solely by medication. On the other hand, when taking a so-called cure he not only has his medicine-i.e., alkaline water internally and externally - but having no business to attend to, no pleasures to follow, his one occupation is to conscientiously carry out in every detail his régime as laid down for him by his adviser, who has him constantly under observation. Given, then, the alkaline treatment-

1 A paper rear before the International Medical Congress at Paris, A paper rear
August 9 th, 1900 . i.e., in this case supplied by use of alkaline waters, good air, a carefully regulated diet, proper exercise, absolute cleanliness, free action of the skin brought about by the use of the alkaline baths, and free action of the kidneys and bowels due to the internal administration of the alkaline wateradded to the knowledge which the patient has that he is doing that for bis condition which is best, can any patient fail to improve?

The first clinical fact which has been impressed upon me is the absence of any clearly defined line of demarkation between the symptoms of cases which have presented them. selves in which a diagnosis of either rheumatism or gout has been made. I have been unable to demonstrate to my own satisfaction any different pathological condition in these socalled diseases, the clinical picture in either case being practically the same. The diagnosis, it would seem, is most often settled by the exciting cause. On the one hand, if the initial attack followed exposure to cold, dampness, \&c., we are most frequently told that it is a case of rheumatism. If, on the other hand, the primary attack was apparently induced by excesses at the table or by indigestion we are said to have a case of gout. The absence of difference in the symptomatology and pathology of the many cases which have come under my observation of so-called rheumatism and gout has led me to discard the terms "rheumatism" and "gont" and bring these conditions under the one general head of " uric acid toxæmia." My own belief being that in the absence of any clearly defined pathological condition neither rheumatism nor gout are true diseases, but are groups of symptoms arising from improper metabolism, or in other words, the effects produced by the retention in the system of the products of metabolism, or waste, I am strengthened in this belief by the observance of two clinical facts. First, that in all the cases which have come under my personal observation in which either a diagnosis of gout or rheumatism has been made, the retention of uric acid has always been readily demonstrated. Secondly, that immediately the free excretion of uric acid was brought about the symptoms have disappeared, irrespectively as to whether the diagnosis has been rheumatism or gout. My universal experience has been that on presentation the so-called case of rheumatism or gout is found to be excreting less than the normal amount of uric acid, and after being put under treatment this amount gradually increases, and with its increase a diminution of the symptoms. The amount of uric acid excreted under treatment is frequently found to be twice or three times greater than before treatment was begun, and then gradually diminishes until the normal mark is reached, at which it remains so long as the patient continues so to conduct his life and habits as will insure bis maintaining a proper relation between waste and repair. The ground being taken that uric acid retention is the indication at least, if not the prime factor in the causation, of such a condition or conditions, which I name " uric acid toxæmia," it follows that the knowledge of the exact amount of uric acid daily excreted is most essential. The ordinary routine of instructing a patient to bring to his medical man "a bottle of urine," with no instruction as to amount or how and when the same is to be collected being given, is useless.

Neither a qualitative analysis nor a microscopic determination will suffice-the first owing to the fact that that particular portion of the daily amount of urine may contain a greater or lesser percentage or the entire output of uric acid; the second owing to the fact that the drop or drops examined may contain all or none of the crystallised uric acid present, and thus lead to error in judging the amount excreted. Obviously a quantitative analysis is necessary. My procedure is as follows. A thoroughly clean glass vessel large enough to contain the output of urine for 24 hours is given the patient, with instructions to collect all urine passed for the following 24 hours; he is also instructed to first empty the bladder whenever having a bowel movement, so that no urine may be lost. From this a quantitative analysis is made, no change of diet having been ordered up to this time. From the evidence gathered from this first analysis treatment is the following day begun, and the patient is instructed as regards diet, exercise, and the use of the waters. On the day following a second analysis is made, the treatment as regards diet, baths, \&c., being changed in accordance with the results of uric acid excretion as shown by said analysis. Analyses are continued every two or three days throughout the treatment which is ended when the excretion of uric acid has reached the normal, the patient then being allowed to return to his home 
after having been instructed as to his manner of living so as to maintain a proper excretion of uric acid. A record of the amount of uric acid excreted is kept in each case from day to day, and on this record, as I have said, is based any change in diet, baths, \&c. It is not claimed that the use of the alkaline treatment as supplied by nature is a specific, but that its employment, owing to the conditions by which it is surrounded, gives a larger percentage of good results. In my experience I may say that next to the internal administration of the alkalies and their external application in the form of baths diet plays the most important part, and by which Haig has shown and my own experience has proved uric acid excretion can be controlled. A dietary is to be carefally followed, not by any set rule to be applied to all cases alike, but by suiting the new diet to each patient in accordance with the indication as shown by the urinary analysis, remembering the importance of personal individuality.

The utility of the alkaline bath has been a vexed question, many practical men holding that there is no absorption of the mineral contents of the water, and many experiments have been made to prove this. My own experience leads me to believe that the taking of the alkaline baths alone will induce an increased uric acid excretion, my theory being that we here again have applied that old physical law of exosmosis and endosmosis, an acid condition of all the tissues, an alkaline medium-i.e., the bath-and an animal membrane-i.e., the skin-intervening. The alkaline treatment, as supplied by alkaline thermal waters, I use in the following manner. A patient is given a daily alkaline bath, varying in temperature from $90^{\circ}$ to $105^{\circ} \mathrm{F}$., for a period of from 5 to 25 minutes. He is given none but alkaline water to drink, a portion being taken on an empty stomach. He takes from two to four hours' active exercise daily and his diet is specifically ordered him. No form of alcohol is permitted, all the different factors of the treatment being regulated by the excretions of uric acid as shown by the analyses. The results in an experience of a number of years have been most satisfactory.

I would call attention to the following essential points in the use of alkaline water for the treatment of uric acid toxæmia: (1) frequent quantitative urinary analyses; (2) changing the diet, the amount of exercise, and the amount of water taken until there is a free excretion of uric acid; (3) the taking of sufficient exercise for the thorough oxidation of the foods taken : (4) the putting aside of all mental work; (5) a specific diet ordered, not depending upon the patient's knowledge as to what contains or does not contain the proximate principles which are to be avoided; and (6) to teach the patient what nature's laws are as pertaining to his health and well-being and how to follow them.

In conclusion, let me deny the statement that has so often been made that there is a great difficulty in making patients follow stringent rules. Such has not been my experience when I have had ability sufficient to impress them with the importance of these restrictions. This treatment, as I have tried to show, is in no way specific. It is not claimed that there is any magic in the waters used, but that it is merely an application and use of the recognised utility of the alkalies, augmented by the surroundings and conditions possible when the patient is so placed as to be constantly under the observation of his physician. The treatment is a rational one and a true exponent of the practice of physiology - a step I trust towards brushing away some of the mysteries which, unfortunately, have surrounded many medical measures. I hope in the near future that it may be said of our profession, "They practise physiology and not medicine."

Virginia, U.S.A

\section{THE WEDGE OPERATION FOR EN- TROPION AND TRICHIASIS.}

BY H. HERBERT, F.R.C.S. ENG.,

MAJOR, I.M.S. ; ACTING OPHTHALMIC SURGEON AND PROFESSOR OF OPHTHALMOLOGY, GRAYT MEDICAL COLLEGE, BOMBAY.

WITHrN the space of one and a half years, some years ago, I operated on 130 upper lids for entropion and trichiasis by Snellen's method, slightly modified, with excellent results A large majority of the cases requiring it were those of combined entropion and trichiasis, some of them being very bad cases indeed. The ordinary Snellen s operation is insutticient for many of our old negiected

cases, and success in these depends entirely on the observance of the details pointed out below. If the necessary rules are followed the operation is equally suited to the mildest and to the most severe cases, to trichiasis as well as to entropion. The ordinary operation consists simply in the removal of a wedge of tarsus with its overlying muscle, the necessary incision having been made through the skin, and the parts are adjusted by Snellen's suturing. The points on which I wish to insist are as follows :

1. A strip of skin two millimetres or more broad should be cut away, at least in all bad cases, unless the skin be contracted and scanty. Otherwise it is redundant afterwards and the upper lip of the wound tends to overhang the lower. It leads to no shortening of the lid beyond that produced by the excision of tarsus.

2. (a) The depth of the tarsal wedge removed should in all cases be sufficient to divide completely the tarsus. If the conjunctiva be penetrated in places no harm results. The whole thickness of the tissue being divided it is found that the conjunctiva and subconjunctival tissue are sufficiently loose or extensile to permit of very considerable displacement as well as rotation of the lower segment of tarsus, which carries with it, of course, the border of the lid. (b) The breadth of the wedge at its base depends largely on the degree of entropion existing. When the lower portion of the tarsus is much thickened and bent the rounded swelling of its anterior surface renders it an easy matter, and indeed almost imperative, to remove a broader wedge than usual. But in some of the older cases of entropion the tarsus is much contracted vertically and the thickening involves the whole or greater part of it. Care has to be taken in these cases not to remove too much or the wedge may easily be made to include the greater portion of the tarsus. (c) The position of the wedge is important. The strip taken should be as near the free margin of the lid as possible-i.e., immediately above the roots of the eyelashes. Thus we have quite a narrow strip of tarsus left below and a comparatively broad plate above, so that when the anterior surfaces of the two are drawn-together any displacement which may occur will be in the lower and not in the upper piece. The broad plate above affords a fixed basis from which one can work on the more readily moved and more readily moulded narrow marginal strip, with sutures.

3. It is in the suturing that Snellen's operation most distinctly fails to make the most of its opportunities (Fig. A.) The sutures should be entered as in Green's operation. The curved needle is to be introduced a little behind the most posterior lashes, wherever they may be situated, and passed obliquely forwards and upwards, to be brought out immediately above the lower

FIG, A.

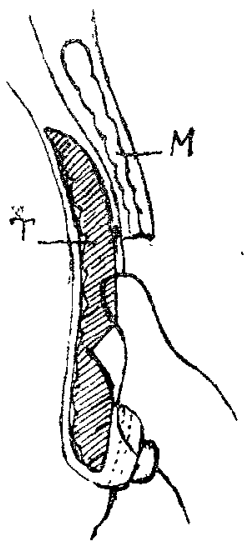

Snellen's suture. I is muscle. $T$ is tarsal cartilage.

margin of the skin wound. Thus the more the trichiasis or districhiasis the further back will the point of entry be, and when the sutures are pulled upon the more wil the border of the lid be brought forward. (Fig. B.) The needle should then be passed into the anterior surface of the upper piece of tarsus distinctly above the cut surface, and brought out again after taking a firm hold; neither skin nor muscle is taken up. Introduced into the tarsus thus the sutures when tightened have distinctly more effect in bringing the eyelashes forward than when introduced "through the upper lip of the tarsal loss of 